\title{
The Other-Race Effect in Caucasian and Japanese-Descendant Children in Brazil: Evidence of Developmental Plasticity
}

\author{
Ana Carolina Monnerat Fioravanti-Bastos ${ }^{1 *}$, Alberto Filgueiras ${ }^{2}$, J. Landeira-Fernandez ${ }^{2}$ \\ ${ }^{1}$ Psychology Department, Federal Fluminense University, Rio das Ostras, Brazil \\ ${ }^{2}$ Psychology Department, Pontifical Catholic University of Rio de Janeiro, Rio de Janeiro, Brazil \\ Email: fioravanti@fioravantiana.org
}

Received 22 September 2014; revised 17 October 2014; accepted 12 November 2014

Copyright (C) 2014 by authors and Scientific Research Publishing Inc.

This work is licensed under the Creative Commons Attribution International License (CC BY). http://creativecommons.org/licenses/by/4.0/

c) (i) Open Access

\begin{abstract}
The Other-Race Effect has been confirmed by several experimental studies, in which the individual has greater difficulty in recognizing the faces of races that are different from their own. Few studies have investigated this effect during the development of the face processing system. The aim of this study was to investigate the development of the Other-Race Effect in Caucasian and Japanesedescendants children born and living in Brazil. Seventy-four children, split into two age groups (5 7 and 9 - 11 years of age), were tested. Japanese-descendant children did not present the effect in favor of their own-race faces, whereas Caucasian children demonstrated the effect in both age groups. This indicates that the effect is present early in the development of face recognition and that contact with the faces of another race during childhood dissipates it. These findings suggest that experience with faces from the children's visual context is crucial for shaping face processing.
\end{abstract}

\section{Keywords}

Face Recognition, Other-Race Effect, Development, Culture

\section{Introduction}

Nature versus nurture is an extensive debate in several fields of science. Some aspects of human conditions show evidence to support a stronger influence of biological and genetic predisposition rather than experience or social interaction, such as the Down Syndrome (Palomaki et al., 2012)—caused by genetics; or, in a less proportion, the Schizophrenia (Greenwood et al., 2013). However, some aspects are in fact related to experience, learn-

\footnotetext{
*Corresponding author.
}

How to cite this paper: Fioravanti-Bastos, A. C. M., Filgueiras, A., \& Landeira-Fernandez, J. (2014). The Other-Race Effect in Caucasian and Japanese-Descendant Children in Brazil: Evidence of Developmental Plasticity. Psychology, 5, 2073-2083. 
ing and social behaviors rather than its genetic basis such as the visual perception (Johnson, 2011), or violence and aggressiveness (Reif et al., 2007). Indeed what seems to happen is that both genetics and environment are sides of the same coin playing both pivotal roles in human cognition.

The developmental psychology brings to the table several contributions to this discussion. For example, there are some evidences supporting the hypothesis that children with ADHD can benefit with working memory training, which leads to improvement in terms of focus of attention (Holmes et al., 2010). These findings suggest that environment and experience are very important to the development of perception and attention. Regarding human perception, the ability to recognize a face among several different faces is one of the most intriguing abilities of humans. Since birth, we have encountered thousands of faces everyday that vary in terms of identity, gender, age, and race. However the question whether face recognition has its own biological foundation or is learned through experience remains unanswered. Face recognition involves the processing and interpretation of a set of visual stimuli, which depend on several factors such as the gender, age, and race of the face.

Studies have shown that children have remarkable abilities of face recognition very early in life, demonstrating that these abilities depend both on innate mechanisms—nature, and experience—nurture. Perceptual abilities for face processing begin early in development and improve as the child develops (Crookes \& McKone, 2009). Several studies indicate that face recognition memory in children improves greatly until approximately 5 years of age (Carey, Diamond, \& Woods, 1980; Crookes \& McKone, 2009), and other races face recognition and age information are represented at the same hierarchical level in young children's memory (Macchi Cassia, Luo, Pisacane, Li, \& Lee, 2014). Indeed, sustained attention (i.e., focused concentration) improves until at least 10 years of age (Betts, McKay, Maruff, \& Anderson, 2006) and narrowing of visual attention focus, visual acuity, and sustained attention contributes to explicit memory performance in a wide range of tasks (Diamond \& Carey, 1986).

Crookes and McKone (2009) demonstrate differences in face recognition in two groups of 5- to 7-year-old and 9- to 11-year-old children, indicating that the ability of children to encode and store faces is as effective as those of adults and that substantial enhancement in experimental task performance after 5 - 7 years of age reflect improvements in general cognitive abilities. This corroborates the assumption that the advantage of face memory in older children and adults is explained by differences in attention or interest that affect explicit memory (Mondloch, Geldart, Maurer, \& Grand, 2003). Crookes and McKone (2009) suggest that, although changes in the velocity of perception may occur in older children, the maturity of processes related to the accuracy of face recognition emerges early in development to a maximum at 5 - 7 years of age.

One of the most important aspects in face recognition is the other-race effect (ORE). The ORE corresponds to the condition in which the person is more inclined to respond correctly when identifying faces of their own race, when comparing to other races faces (Chiroro \& Valentine, 1995). Indeed, other-race faces appear more similar to each other than the faces of one's own race. The ORE has been widely replicated in several laboratories and natural settings (Chance \& Goldstein, 1996).

There are several evidences supporting that the ORE relies on both early visual perception development and experience with a race (Anzures et al., 2012, 2014; Bukach, Cottle, Ubiwa, \& Miller, 2012; Kelly et al., 2007). Studies focusing on the development of the ORE during early childhood can shed some light on how this effect relies on both genetics and experience. The first year of life is pivotal for the development of the ORE (Anzures et al., 2013; Goodman et al., 2007; Kelly et al., 2007). Two different functions seem to contribute in larger part for the emergence of this effect: visual representation of faces and social interaction. Newborns show no preference towards a race; however at the age of 3 months old, children show preference for their own races. This phenomenon is probably due to the development of a visual representation of their own-race rather than 3 months of experience with the child's own race. However, 4-month old children tend to present visual processing for their own and other races, thus, despite of preference, it is early in the child's life in which experience plays a role in building the ORE (Anzures et al., 2013; Liu et al., 2011).

Goodman et al. (2007) demonstrated that despite nationality or biracial context, children from 8 years old and adults recognized faces of their own race more accurately than other race faces. In a longitudinal study with children of 3-, 6- and 9-months old, evidence suggests that children with 3 months of age is only capable of differentiating between faces regardless of race; however ORE emerges at 6 months of age because children can distinguish between own-race and other-race faces, being the ORE present at 9 months old when children only recognize their own-race faces (Kelly et al., 2007). These results show that exposure to other race faces during early childhood does not influence the development of the ORE probably because developmental influences on 
face processing-i.e., the difficulty in paying attention in configural processing, and preclude the ORE under certain conditions.

The development of the ORE seems to rely on featural/configuaral face processing (Goodman et al., 2007). The featural encoding processing is the ability to identify a face paying more attention to their individual features, isolated, then the relationship between these features-configural processing. The ORE can be explained by the fact that people attend to less features information from other race faces than own race faces (Walker \& Tanaka, 2003). As a consequence of young children's cognitive immaturity, they tend to pay more attention to facial features than the relation between the features, explaining the differences in the magnitude of the ORE. between younger and older children (Goodman et al., 2007).

Regardless of those evidence in ORE developing, Anzures et al. (2013) stress out the importance of experience throughout the entire early childhood. Evidence supports the hypothesis of plasticity in the ORE until the end of childhood. Accordingly, Walker and Hewstone (2006), reported a study in which the ORE was examined in two racially segregated communities in United Kingdom-White and South Asian. They found that the ORE was only present in the White community which is the majority race. These results support the prediction that individuals with more interracial experience might have better recognition abilities of other races faces and consequently disrupting the ORE (Walker \& Hewstone, 2006).

The acquisition of these special skills to recognize faces from their own racial group but not to other race groups might be responsible for the ORE (Kelly et al., 2007; Sangrigoli \& De Schonen, 2004). Developmental studies indicated that ORE is already present among 5 year-old children (Pezdek, Blandon-Gitlin, \& Moore, 2003). Indeed, there are some evidence showing that Korean adults who were raised in Korea from 4 to 9 years of age before being adopted by European Caucasian families presented a reversed ORE-i.e., these subjects recognized European faces more accurately than Korean faces (Sangrigoli, Pallier, Argenti, Ventureyra, \& de Schonen, 2005). In a similar study, it was found that Asian children between 6 and 14 years of age who were adopted by European families between 2 and 26 months of age did not present an ORE for Asian nor Caucasian faces (De Heering, De Liedekerke, Deboni, \& Rossion, 2010). These findings support the assumption that the face processing system is regulated by the interaction with the environment and can be deeply modified by experience during early childhood.

All in all, evidence shows that the ORE begins early in life. Infant and toddlers tend to prefer to look to their own race faces rather than other races, which suggests an influence of the biological portion of the human cognition. Nonetheless, it is possible to see changes in the ORE through children's development, but significantly less as children grow old. Thereby, ORE seems to have a critical period for changing or plasticity-i.e., after a certain age children have more difficulty in recognizing faces of races other than the ones they were raised amongst. Changes during the development of the ORE seem to be influenced in a larger part by experience and environment. Discrepant evidences found in the literature regarding the critical period of the plasticity of the ORE justify the main objective of the present study. We sought to investigate the development of the ORE in 5 7 and 9 - 11 years old children from two different races who were born and living in the same country, seeking to find critical period for the ORE.

\section{Methods}

\subsection{Participants}

A group of 74 Brazilian and Japanese-descendant children who were born and lived in Rio de Janeiro and Niterói were split into two age range groups. The selection of age groups was based on previous studies, about the maturity of face recognition and studies in which the ORE was found during childhood (Crookes \& McKone, 2009; Goodman et al., 2007). The first age group included 19 Caucasian and 19 Japanese-descendant children within the range of 5 to 7 years of age. The second age group included 18 Caucasian and 18 Japanese-descendant children within the range of 9 to 11 years of age. The Japanese-descendant children from both age groups attended activities at the Nikkey Society —Cosme Velho, Rio de Janeiro; and Tingá, Niterói, Brazil. In their daily routine, these children attend Brazilian schools, having much contact with Caucasian children. They also attended daily Nikkei society for dance classes, theater, martial arts, crafts, culinary and festive gatherings on weekends. The Nikkei society is an association that promotes the culture of Japan for Japanese-descendant living in Brazil, thereby only Japanese people or their descendants participate on those activities (for more information about the Nikkei society, see http://www.nikkeirj.com.br/). 
The Caucasian children were students from Dispensário Santa Terezinha do Menino Jesus at Gávea in Rio de Janeiro, Brazil and Golfinho Feliz child daycare center in the city of Niterói, Brazil. All of the participants were tested in their study environments while performing normal activities. Table 1 presents the age and gender distribution of these two samples used in the present study.

Parents agreed to let their children participate of this study by signing a Statement of Consent regarding privacy of data and publicity of the results. This work received ethical approval from the Research Ethical Committee of the Psychology Department at the Pontifícia Universidade Católica do Rio de Janeiro, Brazil prior to commencement of the research.

\subsection{Stimuli}

Twelve colored frontal view photographs of the faces of Caucasian children (six male and six female) and 12 colored frontal view photographs of the faces of Japanese children (six male and six female) were kindly provided by Prof. Kang Lee of the Institute for Child Studies at the University of Toronto, Canada. The photographs of the faces were cut into oval shapes $(493 \times 493$ pixels $)$ with $11.5 \times 6.3$ centimeters. The images were cropped to eliminate cues such as hair and earrings. According to the literature, the hair (Toseeb, Keeble, \& Bryant, 2012), as other cues, plays essential roles on face recognition and could represent a bias in the present study. From the 12 Caucasian faces (six males and six females) and 12 Japanese faces (six males and six females), 12 pairs of faces were generated: six pairs of Caucasian faces (three male pairs and three female pairs) and six pairs of Japanese faces (three male pairs and three female pairs). Each face appeared four times, twice as a target (left and right side) and twice as a non-target (left and right side), for a total of 96 trials. The faces were displayed on a 15-inch flat-screen monitor on a Dell Latitude D505 Intel Pentium-M 1.6 GHz notebook computer placed at $57 \mathrm{~cm}$ from the children.

\subsection{Procedure}

The participants were individually tested in a matching-to-sample task programmed in Inquisit 3.0 from Millesecond Software which is recommended for reaction-time tasks (Stahl, 2006). The first task was formulated as a control task to avoid the possibility that the differences in the face recognition memory were caused by external factors, such as cognitive differences or difficulties dealing with the program and/or the computer. In the first task, eight objects were selected for the memory task (i.e., hat, umbrella, acoustic guitar, bag, shoe, pencil, apple, rose).

Each trial consisted of the display of a target object in the center of the screen for 500 milliseconds, followed by two objects presented side by side after a 1 second interstimulus interval (ISI) gray screen. The objects remained on the screen until the participant pressed one of the two response buttons to indicate which picture matched the target. Responses were made with the right and left index fingers, and the participant was instructed to respond as fast and accurately as possible. No feedback was given. The intertrial interval (ITI) was 1 second after each response. The participants performed two blocks of trials in one session. The first block was a training block with eight trials, and the participants were told that the responses were not recorded.

The second block began immediately after the first block was finished and consisted of 32 trials that used the same set of eight objects presented successively in a different random order. In a block, each object was presented a total of four times (twice as a target and twice as a non-target; twice on the right side and twice on the left side of the screen). The order of the presentation of the targets was the same for all participants. After this task was completed, the participants were asked to remain sit for the second task.

Table 1. Age and gender distribution of Japanese-descendant and Caucasian children split by age group. Age range 1: 5 - 7 years old. Age range 2: 9 - 11 years old.

\begin{tabular}{cccccccccc}
\hline \multirow{2}{*}{ Group } & \multicolumn{3}{c}{ Age Range 1 } & \multicolumn{5}{c}{ Age Range 2 } \\
\cline { 2 - 10 } & Age (SEM) & Female & Male & Total & Age (SEM) & Female & Male & Total \\
\hline Japanese & $5.78(0.20)$ & $52.63 \%$ & $47.37 \%$ & 19 & $10.30(0.19)$ & $50.00 \%$ & $50.00 \%$ & 18 \\
Caucasian & $5.98(0.15)$ & $57.98 \%$ & $42.11 \%$ & 19 & $10.11(0.19)$ & $50.00 \%$ & $50.00 \%$ & 18 \\
Total & $5.84(0.12)$ & $55.26 \%$ & $44.74 \%$ & 38 & $10.19(0.14)$ & $50.00 \%$ & $50.00 \%$ & 36 \\
\hline
\end{tabular}


The second task followed the same procedure as the first with exception of stimuli. It was referred as the Face Recognition Test (FRT), and each trial consisted of displaying a target face in the center of the screen for 500 milliseconds, followed by two faces presented side by side after an ISI of 1 second - a gray screen. The faces remained on the screen until the participant pressed one of two response buttons to indicate which picture matched the target. Responses were made with the right and left index fingers, and the participant was instructed to respond as fast and accurately as possible. No feedback was given. Each participant performed two blocks of trials in one session. The first block was the training block with eight trials. The images used in the training block were cartoons, not photographs. The participants were told that the responses were not recorded. The second block began immediately after the first block, and consisted of two sets of six pairs of faces photographs divided in 96 trials as described at the "stimuli" section. The pair of photographs was presented successively in a different random order. In a block, each face was presented a total of four times (twice as a target and twice as a non-target; twice on the right side and twice on the left side of the screen). The order of the presentation of the targets was the same for all participants. Reaction time and Errors were recorded. When finished this task, subjects has and interval of 20 to 30 minutes to rest, before beginning the next tasks. Soon after the break, each participant was asked to participate in a memory test that was applied to avoid the effects of external variable bias between groups. Figure 1 depicts the procedure for one trial in both the control task and the FRT.

The test was the Finger Window Card Subtest from the Wide Range Assessment of Memory and Learning test (WRAML) (Sheslow \& Adams, 1990). The WRAML test was designed to be an inclusive memory battery that is standardized for children between 5 and 17 years of age. An advantage of using a test such as the WRAML is that it provides a number of memory tasks that are all based on a common normative group and that have known inter-correlations and factor structure. This allows for meaningful comparisons across tasks, within and between groups.

The Finger Window Card Subtest requires the participant to recall the sequential placement of a pencil by the examiner into a series of holes placed in a plastic card. The sequences start with two numbers and progress through seven-number sequences. The test score is the number of entire sequences that the participant completes. This test is considered a measure of spatial working memory.

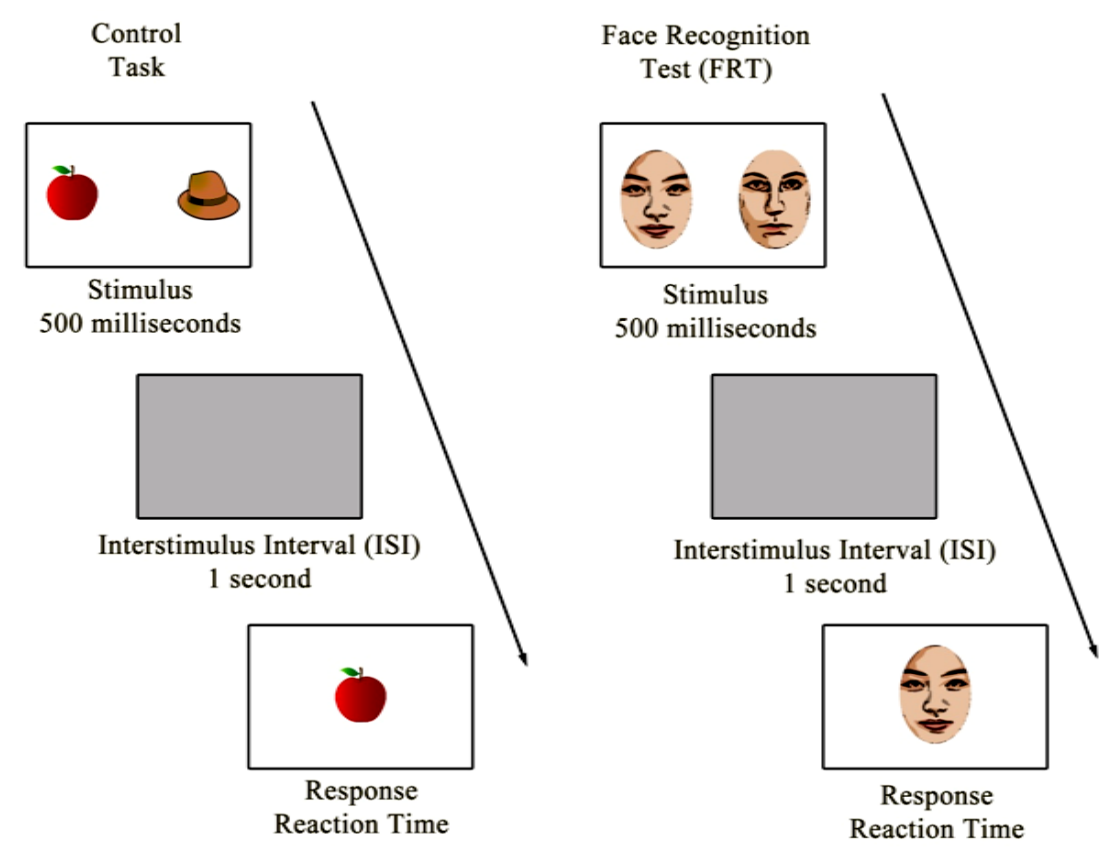

Figure 1. Examples of trials for both the control task-object recognition; and the FRT. The participant was first asked to look at two stimuli for 500 milliseconds. The ISI of 1 second consisted of a grey screen following the two stimuli presentation. After that, the participant had to press the spatial compatible button- " $A$ " if the left stimulus or " $L$ " if the right stimulus - to answer which stimulus of those two previously presented was corresponded to the target. The ITI was 1 second. 


\subsection{Statistical Analysis}

The main purpose of this study was to investigate the development of the ORE between two age groups of Caucasian and Japanese children. Each group's reaction times on all responses in the recognition of Caucasian and Japanese faces were recorded. Descriptive analyses were employed to demonstrate the sample means and standard errors of the mean (SEMs) in the tasks. A 2-way ANOVA was used to detect differences among groups in the Object Recognition Test and Test Finger Window Subtest.

The FRT statistical analyses were conducted with the correct responses only. There were no outlier treatment since there were no participants with results above two standard deviations in neither groups, thus, probably the data were not degraded. To analyze differences between groups in the FRT, we used a 3-way analysis of variance (3-way ANOVA), for age groups (5 to 7 years of age; 9 to 11 years of age), race groups (Caucasian; Japanesedescendant) and face types stimuli (Caucasian; Japanese) to compare children's mean reaction time and error means. Effect size for all ANOVA was measured by omega squared $\left(\omega^{2}\right)$. We used the Fisher's Least Significant Difference (LSD) post hoc test to verify differences within children.

\section{Results}

\subsection{Object Recognition Test}

Figure 2 shows the differences in the mean reaction times on the Object Recognition Test in Caucasian and Japanese-descendant children in the two age groups. In the first age group (5 - 7 years of age), Japanese-descendant children had a mean reaction time of 947.73 (SEM = 36.43) milliseconds (ms.), whereas Caucasian children had a mean reaction time of 956.73 (SEM = 59.66) $\mathrm{ms}$. In the second age group ( 9 - 11 years of age), Japanese-descendant children had a mean reaction time of 558.20 (SEM = 38.27) ms., and Caucasian children had a mean reaction time of $652.46(\mathrm{SEM}=52.65) \mathrm{ms}$. The 2-way ANOVA revealed no interaction between race and age groups $\mathrm{F}(1,73)=0.878, p=0.35, \omega^{2}=0.11$, however, the main effect presented significant differences between collected data $\mathrm{F}(1,73)=20.386, p<0.001, \omega^{2}=0.83$. Age groups factor revealed significant differences $\mathrm{F}(1,73)$ $=59.851, p<0.001, \omega^{2}=0.96$, and no significant differences for race groups $\mathrm{F}(1,73)=0.464, p=0.49, \omega^{2}=$ 0.23 .

\subsection{Finger Window Subtest}

Figure 3 shows the differences in mean scores on the Finger Window Subtest in Caucasian and Japanese-descendant children in the two age groups. In the first age group (5 - 7 years of age), Japanese-descendant children had a mean score of 9.42 (SEM = 0.43), and Caucasian children had a mean score of 9.32 (SEM = 0.40). In the second age group (9 - 11 years of age), Japanese-descendant children had a mean score of 12.89 (SEM = 0.39), and Caucasian children had a mean score of 12.22 (SEM = 0.42). A 2-way ANOVA showed no interaction between race and age groups $\mathrm{F}(1,73)=0.792, p=0.38, \omega^{2}=0.15$. The main effect presented significant differences for finger window mean scores $\mathrm{F}(1,73)=18.125, p<0.001, \omega^{2}=0.84$. Age groups revealed significant differences $\mathrm{F}(1,73)=9.962, p<0.001, \omega^{2}=0.79$, although no significant differences for race groups $\mathrm{F}(1,73)=$ $1.162, p=0.29, \omega^{2}=0.19$, suggesting cognitive differences between older and younger children, but no cognitive differences between Caucasian and Japanese-descendant children.

\subsection{Face Recognition Test}

Figure 4 shows the differences in the participants' mean reaction times in the recognition of Caucasian and Japanese faces divided by age group. In the first age group ( $5-7$ years of age), Caucasian children had a mean reaction time of 1634.61 (SEM = 61.23) ms. recognizing Caucasian faces and 1481.19 (SEM = 77.98) ms. recognizing Japanese faces. Japanese-descendant children had a mean reaction time of 1185.39 (SEM = 69.04) ms. recognizing Caucasian faces and 1332.86 (SEM = 85.56) ms. recognizing Asian faces.

In the second age group ( 9 - 11 years of age), Caucasian children had a mean reaction time of 991.67 (SEM = 82.86) ms. recognizing Caucasian faces a mean reaction time of 1281.39 (SEM = 88.06) ms. recognizing Japanese faces. Japanese-descendant children had a mean reaction time of $844.22(\mathrm{SEM}=65.34) \mathrm{ms}$. recognizing Caucasian faces and 884.97 (SEM = 68.18) ms. recognizing Japanese faces.

The mixed-ANOVA showed, regarding the Between-Subjects Effects, no three-way Face Type $\times$ Age Range $\times$ 


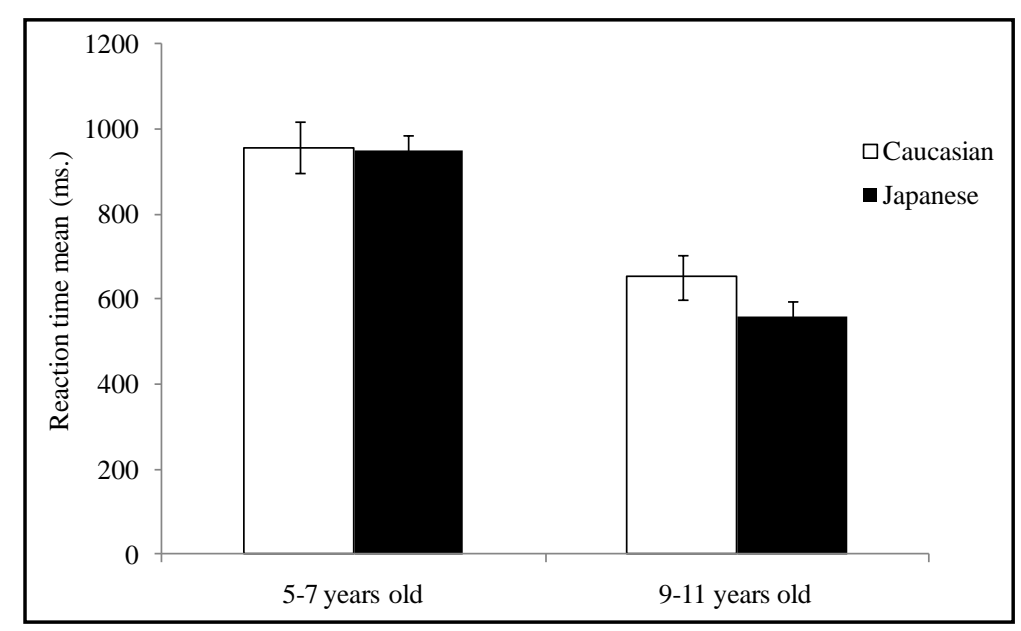

Figure 2. Mean reaction times in the Object Recognition Test in Caucasian and Japanese children. The children are split by age group.

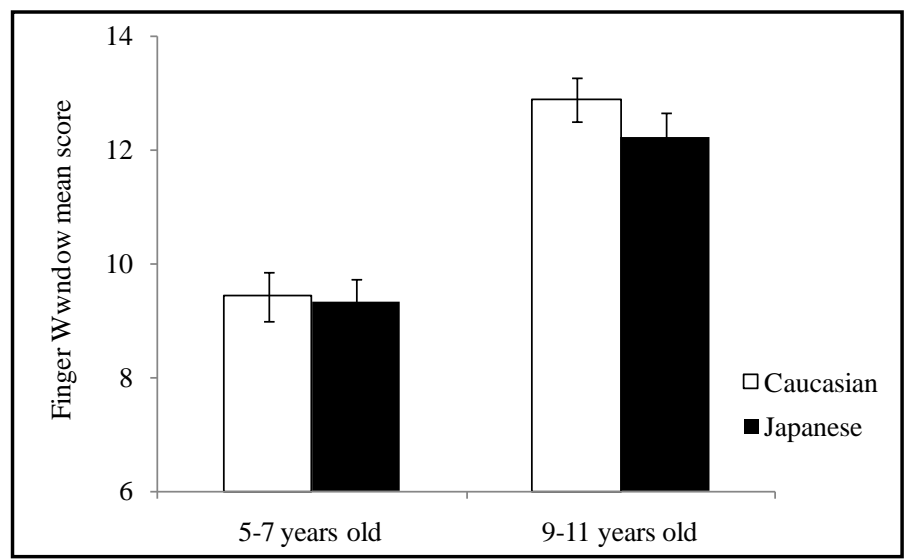

Figure 3. Mean scores on the WRAML Finger Window Subtest in Caucasian and Japanese children. The children are split by age group.

Race interaction $\mathrm{F}(1,147)=0.96, p>0.3, \omega^{2}=0.08$. The same statistical analysis revealed a two-way interaction between Race x Face Type $\mathrm{F}(1,147)=8.89, p<0.05, \omega^{2}=0.73$, indicating that performance in the recognition of Caucasian and Japanese faces depends on the children's race. Inspection of Figure 4 indicates that Caucasian children recognize Caucasian faces more quickly than Japanese faces. This interaction was not associated with the children's age group because the three-way interaction was not significant. No significant Face Type $\mathrm{x}$ Age Range interaction was found $\mathrm{F}(1,147)=1.85, p>0.17, \omega^{2}=0.21$, demonstrating that the recognition of Caucasian and Japanese faces was similar in both age groups (i.e., 5 - 7 and 9 - 11 years of age). Figure 4 depicts that the 5- to 7-year-old group had higher reaction times than the 9- to 11-year-old group. We also found no Age Range $\times$ Race interaction $\mathrm{F}(1,147)=0.59, p>0.44, \omega^{2}=0.18$, indicating that the Japanese-descendant children, regardless of age group, had faster reaction times than the Caucasian children. Figure 4 also shows that the Caucasian children had more difficulty recognizing the Japanese faces.

The 3-way ANOVA revealed main effects between-subjects for Face Type $\mathrm{F}(1,147)=11.20, p<0.05, \omega^{2}=$ 0.93 , Age Range $\mathrm{F}(1,147)=18.95, p<0.05, \omega^{2}=1.04$, and Race $\mathrm{F}(1,147)=30.91, p<0.05, \omega^{2}=1.16$. The LSD post hoc test revealed differences only Within-Subjects from the Caucasian group-first age group, Caucasian children, $p<0.05$, Japanese-descendant children, $p=0.44$; second age group, Caucasian children, $p<0.05$, Japanese-descendant children, $p=0.134$.

We conducted an error means analysis of the participants' capability to recognize Caucasian and Japanese faces divided by age groups, race groups and face type stimuli. In the first age group ( 5 - 7 years), Caucasian children showed error mean $=8.52($ SEM $=0.78)$ when recognizing Caucasian faces, while presented error 


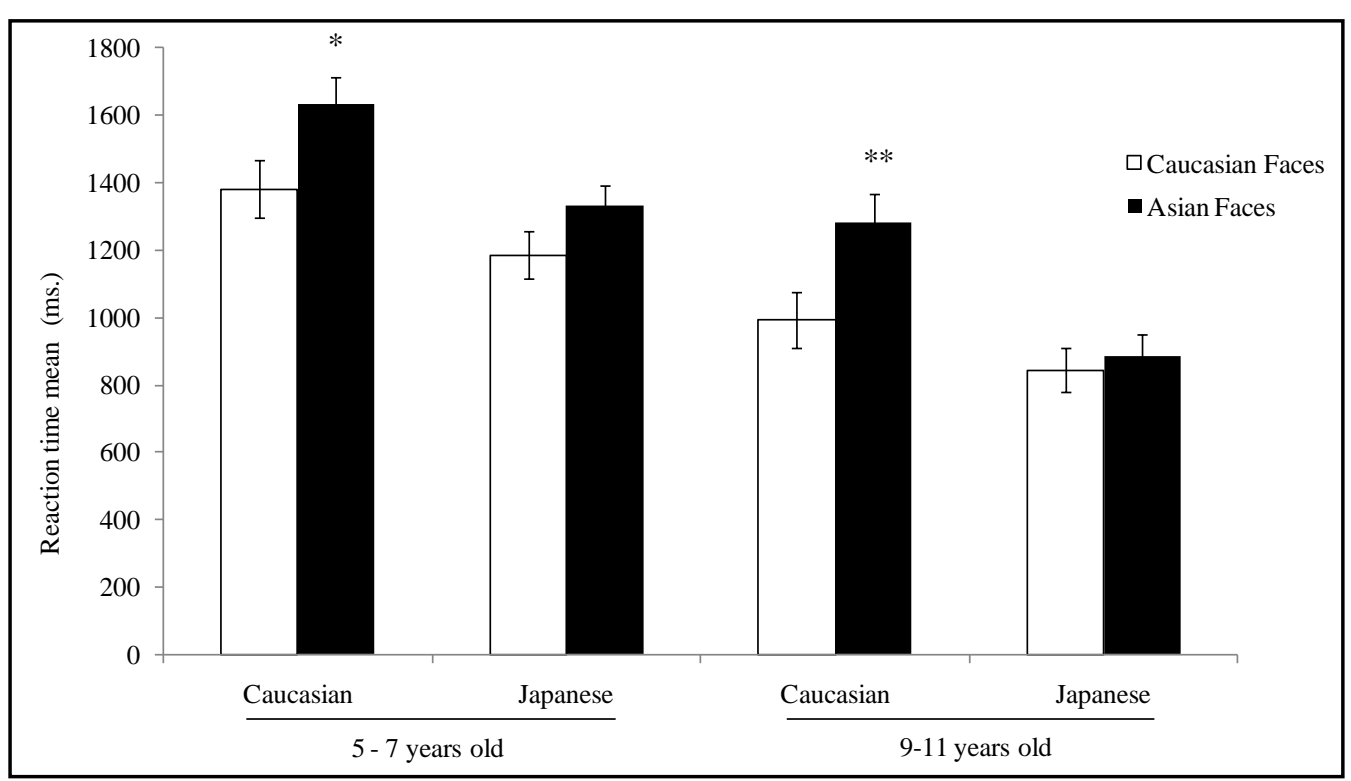

Figure 4. Mean reaction time (milliseconds) in the Face Recognition Test in Caucasian and Japanese children. The children are split by age group. The white bars represent the mean reaction times for Caucasian faces. The black bars represent the mean reaction times for Japanese faces.

mean $=9,15($ SEM $=0.83)$ when recognizing Japanese faces. Japanese-descendant children obtained a mean of $9.26(\mathrm{SEM}=0.72)$ when recognizing Caucasian faces and $9.68(\mathrm{SEM}=0.54)$ when recognizing Japanese faces.

In the second age group $(9-11)$, Caucasian children obtained error mean $=9.61(\mathrm{SEM}=0.85)$ recognizing Caucasian faces, while recognizing Japanese faces they presented an error mean $=9.72$ (SEM $=0.89$ ). Japanesedescendant children obtained error mean $=9.44($ SEM $=0.90)$ to recognize Caucasian faces and $8.55($ SEM $=$ 1.13) recognizing Japanese faces.

The 3-way ANOVA showed no three ways interaction in the Between-Subjects Effects for Type Face, Age Range and Race $\mathrm{F}(1,147)=1.15, p>0.6, \omega^{2}=0.14$, indicating that when taken into account the three variables, the main effect was diluted. No two ways interaction was found between Type Face and Age Range $F(1,147)=$ $0.79, p>0.5, \omega^{2}=0.11$, nor between Age Range and Race $\mathrm{F}(1,147)=1.16, p>0.3, \omega^{2}=0.15$, nor between Type face and Range $F(1,147)=0.56, p>0.4, \omega^{2}=0.13$. These results imply that even being faster, the Japanese children's mean errors behaved the same way as Caucasian children’s.

\section{Discussion}

The results from this study, demonstrated that Caucasian children in both age groups recognized more quickly their own-race faces than faces from the other race, supporting the emergence of the ORE in early childhood. This prediction shows that facial selectivity based on differences in race emerges very early in life-i.e., the first years of age.

According to Kelly et al. (2007), the newly born facial processing system gradually becomes more sensitive to faces of the same race group as a result of increased exposure to these faces. This change in sensitivity reflects the emergence of a lack of improvement in the accurate recognition of faces from unfamiliar groups, which basically explains the presence of the ORE in our Caucasian children.

Interestingly, Japanese-descendant children in both age groups did not exhibit differences in performance when recognizing Caucasian and Asian faces. These results are consistent with several articles (De Heering et al., 2010; Heron-Delaney et al., 2011; Kelly et al., 2007; S. Sangrigoli et al., 2005; Wheeler et al., 2011), in which faces observed in the context of the children's visual development influence face perception preferences that emerge in early childhood. Our findings demonstrate that Japanese-descendant children born and raised in Brazil have much contact with Caucasian faces, at school and in their daily routines, which explains the same speed in recognizing Japanese and Caucasian faces. Indeed, Japanese-descendant children did not exhibit the classic ORE in favor of faces of their own race, which corroborates with Walker and Hewstone (2003), findings about the 
absence of ORE in the minority group in the society.

The Object Recognition Test and Finger Window Subtest revealed that children in the second age group (9 11 years of age) performed better than children from the first age group ( $5-7$ years of age). This effect can be explained by differences in cognitive development in both age groups. These results support the fact that the narrowing of visual attention focus, visual acuity, and sustained attention contributes to poor explicit memory performance in a task (Diamond \& Carey, 1986) and in a face recognition task (Goodman et al., 2007).

These results indicated that our two samples—-the Caucasian and Japanese-descendant—had identical scores in object recognition and in explicit memory, measured by Finger Window subtest, hence, the Caucasian poorer scores in Japanese face recognition is not likely to be due the differences in perceptual and cognitive efficiency of the sample. Age differences were present as younger participants had slower reaction times, indicating that face recognition memory for other-race faces improves with age. Moreover, present results demonstrated that the ORE is present during early childhood, at $5-7$ years of age. Greater contact with individuals of different races is associated with a greater ability to recognize these faces (Chiroro \& Valentine, 1995).

Our findings are consistent with Sangrigoli et al. (2005). In their work, Sangrigoli et al. (2005) tested adults (mean, 23 years of age) who had much experience with other-race faces showing reversed ORE. However, those participants did not hold the same experience with their own-race like our sample. In the present study, Japanese-descendant children attended to a society — the Nikkei Society—-that enhances their contact with their ownrace. The expected in this case is the absence of reversed ORE because their daily contact with both Caucasian and other Japanese-descendants provides them enough experience with both own- and other-race faces.

Our results also fit well with De Heering et al. (2010), who found no reversal of the ORE but rather an attenuation of the effect. This difference may be explained by the fact that when children must discriminate faces from different races, their performance in the task is influenced by the maturity of face processes and their experience with other-race faces, which is consistent with Goodman et al. (2007) findings that cognitive development is an important factor that influences the ORE. However, Goodman et al. (2007) did not find the ORE in younger children suggesting an increased limitation on this field of study: we cannot control the amount of experience children or adults have had so far with their own- or other-race faces.

Those limitations are possible if we investigate the results of Sangrigoli et al. (2005) and De Heering et al. (2010). This second study concerns children adopted much later than in the first study, at a time where it was believed that Korean adoptees had to meet other Korean people. Instead Sangrigoli's adoptees, who were adult at the time of the study, were children at a time where contact with other Korean was not at all encouraged. As a consequence Sangrigoli's adoptees might have had less experience with Asian facial morphology during childhood and adolescence than it was the case for de Heering's adoptees. Our results answer this question regarding the possibility of reversibility of the ORE: it is defined by the amount of experience one has with other or ownrace faces. In a multiracial society such as Brazil, it becomes easier to children to have enough experience with their own-race, even among Japanese-descendants. Thereby, it is evidence that the plasticity of the ORE occurs due to exposure to different types of faces.

The similarity of the results between 5- to 7-years old children and 9- to 11-years old children in other and own-race face recognition also suggests that the emergence and maturity of the ORE can occur before 5 years of age. Indeed, what seems to happen is that in the first year of life, babies have enough contact to other or ownrace faces to build an ORE (Anzures et al., 2013; Anzures, Quinn, Pascalis, Slater, \& Lee, 2010). However, phenomenon like reversibility or attenuation of the ORE seem to be possible arrangements for face recognition at any of life. The present study, thus, showed only the presence of ORE in children starting at 5 years old, not having the success to point out the critical period of the ORE—-which is probably earlier and new studies should take this evidence into account.

The face recognition system is plastic during early childhood, and social interaction can modify the ORE. Therefore, early experience with other races is an important factor in determining the presence of the ORE. These results also emphasize the importance of the length of exposure to new-race faces in stabilizing recently acquired face representations.

Finally, the first question of the present study was how human perception might add evidence to the nature versus nurture debate? Indeed, such as several other articles (Crookes \& McKone, 2009; De Heering et al., 2010; Goodman et al., 2007; Kelly et al., 2007; Sandy Sangrigoli \& De Schonen, 2004; Walker \& Hewstone, 2006), our study shows that experience has a stronger impact in recognition and perception of faces than a genetic or biological predisposition. We do not deny the important role that genetics plays in this field of study, in fact ba- 
bies show preference to their own-race once they can see clearly a face (Anzures et al., 2013). However, at least in this subject, the experience can change our own nature for recognizing faces of other or our own-race faces during early stages of development.

\section{Limitations of the Study}

Despite of the present findings and possible implications regarding the present study, the plasticity hypothesis raised in this discussion is not the only possible explanation. There is no possibility to rule out the explanation that one set of faces-Caucasian or Japanese-is harder to recognize and discriminate while compared to the other. The only way to test this alternative explanation would be to collect data from a control sample of Japanese children living in Japan. If this group of children shows a significant own-ethnicity effect, then this would be a much more compelling evidence of plasticity in the present study's Brazilian-raised Japanese sample.

\section{Acknowledgements}

We sincerely thank all children and parents who participated. Also thank professor Kang Lee, from the University of Toronto, Canada, for the children images used on the experiments. We acknowledge the Nikkey Society, Dispensário Santa Terezinha do Menino Jesus and Creche Golfinho Feliz for open their doors and contributing to the viability of this study.

\section{References}

Anzures, G., Kelly, D. J., Pascalis, O., Quinn, P. C., Slater, A. M., de Viviés, X., \& Lee, K. (2014). Own- and Other-Race Face Identity Recognition in Children: The Effects of Pose and Feature Composition. Developmental Psychology, 50, 469481. http://dx.doi.org/10.1037/a0033166

Anzures, G., Quinn, P. C., Pascalis, O., Slater, A. M., \& Lee, K. (2010). Categorization, Categorical Perception, and Asymmetry in Infants' Representation of Face Race. Developmental Science, 13, 553-564. http://dx.doi.org/10.1111/j.1467-7687.2009.00900.x

Anzures, G., Quinn, P. C., Pascalis, O., Slater, A. M., Tanaka, J. W., \& Lee, K. (2013). Developmental Origins of the OtherRace Effect. Current Directions in Psychological Science, 22, 173-178. http://dx.doi.org/10.1177/0963721412474459

Anzures, G., Wheeler, A., Quinn, P. C., Pascalis, O., Slater, A. M., Heron-Delaney, M., \& Lee, K. (2012). Brief daily Exposures to Asian Females Reverses Perceptual Narrowing for Asian Faces in Caucasian Infants. Journal of Experimental Child Psychology, 112, 484-495. http://dx.doi.org/10.1016/j.jecp.2012.04.005

Betts, J., McKay, J., Maruff, P., \& Anderson, V. (2006). The Development of Sustained Attention in Children: The Effect of Age and Task Load. Child Neuropsychology: A Journal on Normal and Abnormal Development in Childhood and Adolescence, 12, 205-221. http://dx.doi.org/10.1080/09297040500488522

Bukach, C. M., Cottle, J., Ubiwa, J., \& Miller, J. (2012). Individuation Experience Predicts Other-Race Effects in Holistic Processing for Both Caucasian and Black Participants. Cognition, 123, 319-324.

http://dx.doi.org/10.1016/j.cognition.2012.02.007

Carey, S., Diamond, R., \& Woods, B. (1980). Development of Face Recognition: A Maturational Component? Developmental Psychology, 16, 257-269. http://dx.doi.org/10.1037/0012-1649.16.4.257

Chance, J. E., \& Goldstein, A. G. (1996). The Other Race Effect and Eyewitness Identification. In S. L. Sporer, R. S. Malpass, \& G. Koehnken (Eds.), Psychological Issues in Eyewitness Identification (pp. 153-176). Mahwah: Erlbaum.

Chiroro, P., \& Valentine, T. (1995). An Investigation of the Contact Hypothesis of the Own-race Bias in Face Recognition. The Quarterly Journal of Experimental Psychology Section A, 48, 879-894. http://dx.doi.org/10.1080/14640749508401421

Crookes, K., \& McKone, E. (2009). Early Maturity of Face Recognition: No Childhood Development of Holistic Processing, Novel Face Encoding, or Face-Space. Cognition, 111, 219-247. http://dx.doi.org/10.1016/j.cognition.2009.02.004

De Heering, A., De Liedekerke, C., Deboni, M., \& Rossion, B. (2010). The Role of Experience during Childhood in Shaping the Other-Race Effect. Developmental Science, 13, 181-187. http://dx.doi.org/10.1111/j.1467-7687.2009.00876.x

Diamond, R., \& Carey, S. (1986). Why Faces Are and Are Not Special: An Effect of Expertise. Journal of Experimental Psychology: General, 115, 107-117. http://dx.doi.org/10.1037/0096-3445.115.2.107

Goodman, G. S., Sayfan, L., Lee, J. S., Sandhei, M., Walle-Olsen, A., Magnussen, S., Pezdek, K., \& Arredondo, P. (2007). The Development of Memory for Own- and Other-Race Faces. Journal of Experimental Child Psychology, 98, $233-242$. http://dx.doi.org/10.1016/j.jecp.2007.08.004 
Greenwood, T. A., Swerdlow, N. R., Gur, R. E., Cadenhead, K. S., Calkins, M. E., Dobie, D. J., Braff, D. L. et al. (2013). Genome-Wide Linkage Analyses of 12 Endophenotypes for Schizophrenia from the Consortium on the Genetics of Schizophrenia. The American Journal of Psychiatry, 170, 521-532.

Heron-Delaney, M., Anzures, G., Herbert, J. S., Quinn, P. C., Slater, A. M., Tanaka, J. W., \& Pascalis, O. (2011). Perceptual Training Prevents the Emergence of the Other Race Effect during Infancy. PLoS ONE, 6, e19858. http://dx.doi.org/10.1371/journal.pone.0019858

Holmes, J., Gathercole, S. E., Place, M., Dunning, D. L., Hilton, K. A., \& Elliott, J. G. (2010). Working Memory Deficits Can Be Overcome: Impacts of Training and Medication on Working Memory in Children with ADHD. Applied Cognitive Psychology, 24, 827-836. http://dx.doi.org/10.1002/acp.1589

Johnson, S. P. (2011). Development of Visual Perception. Wiley Interdisciplinary Reviews: Cognitive Science, 2, 515-528. http://dx.doi.org/10.1002/wcs.128

Kelly, D. J., Quinn, P. C., Slater, A. M., Lee, K., Ge, L. Z., \& Pascalis, O. (2007). The Other-Race Effect Develops during Infancy: Evidence of Perceptual Narrowing. Psychological Science, 18, 1084-1089. http://dx.doi.org/10.1111/j.1467-9280.2007.02029.x

Liu, S. Y., Quinn, P. C., Wheeler, A., Xiao, N. Q., Ge, L. Z., \& Lee, K. (2011). Similarity and Difference in the Processing of Same- and Other-Race Faces as Revealed by Eye Tracking in 4- to 9-Month-Olds. Journal of Experimental Child Psychology, 108, 180-189. http://dx.doi.org/10.1016/j.jecp.2010.06.008

Macchi Cassia, V., Luo, L. Z., Pisacane, A., Li, H., \& Lee, K. (2014). How Race and Age Experiences Shape Young Children's Face Processing Abilities. Journal of Experimental Child Psychology, 120, 87-101. http://dx.doi.org/10.1016/j.jecp.2013.11.016

Mondloch, C. J., Geldart, S., Maurer, D., \& Grand, R. L. (2003). Developmental Changes in Face Processing Skills. Journal of Experimental Child Psychology, 86, 67-84. http://dx.doi.org/10.1016/S0022-0965(03)00102-4

Palomaki, G. E., Deciu, C., Kloza, E. M., Lambert-Messerlian, G. M., Haddow, J. E., Neveux, L. M., Canick, J. A. et al. (2012). DNA Sequencing of Maternal Plasma Reliably Identifies Trisomy 18 and Trisomy 13 as Well as Down Syndrome: An International Collaborative Study. Genetics in Medicine : Official Journal of the American College of Medical Genetics, 14, 296-305. http://dx.doi.org/10.1038/gim.2011.73

Pezdek, K., Blandon-Gitlin, I., \& Moore, C. (2003). Children’s face Recognition Memory: More Evidence for the CrossRace Effect. Journal of Applied Psychology, 88, 760-763. http://dx.doi.org/10.1037/0021-9010.88.4.760

Reif, A., Rösler, M., Freitag, C. M., Schneider, M., Eujen, A., Kissling, C., Retz, W. et al. (2007). Nature and Nurture Predispose to Violent Behavior: Serotonergic Genes and Adverse Childhood Environment. Neuropsychopharmacology, 32, 2375-2383. http://dx.doi.org/10.1038/sj.npp.1301359

Sangrigoli, S., \& De Schonen, S. (2004). Recognition of Own-Race and Other-Race Faces by Three-Month-Old Infants. Journal of Child Psychology and Psychiatry, 45, 1219-1227. http://dx.doi.org/10.1111/j.1469-7610.2004.00319.x

Sangrigoli, S., Pallier, C., Argenti, A. M., Ventureyra, V. A. G., \& De Schonen, S. (2005). Reversibility of the Other-Race Effect in Face Recognition during Childhood. Psychological Science, 16, 440-444.

Sheslow, D., \& Adams, W. (1990). Wide Range Assessment of Memory and Learning. Wilmington: Jastak Associates.

Stahl, C. (2006). Software for Generating Psychological Experiments. Experimental Psychology, 53, 218-232. http://dx.doi.org/10.1027/1618-3169.53.3.218

Toseeb, U., Keeble, D. R. T., \& Bryant, E. J. (2012). The Significance of Hair for Face Recognition. PLoS ONE, 7. http://dx.doi.org/10.1371/journal.pone.0034144

Walker, P. M., \& Hewstone, M. (2006). A Perceptual Discrimination Investigation of the Own-Race Effect and Intergroup Experience. Applied Cognitive Psychology, 20, 461-475. http://dx.doi.org/10.1002/acp.1191

Walker, P. M., \& Tanaka, J. W. (2003). An Encoding Advantage for Own-Race versus Other-Race Faces. Perception, 32, 1117-1125. http://dx.doi.org/10.1068/p5098

Wheeler, A., Anzures, G., Quinn, P. C., Pascalis, O., Omrin, D. S., \& Lee, K. (2011). Caucasian Infants Scan Own- and Other-Race Faces Differently. PLoS ONE, 6. http://dx.doi.org/10.1371/journal.pone.0018621 
Scientific Research Publishing (SCIRP) is one of the largest Open Access journal publishers. It is currently publishing more than 200 open access, online, peer-reviewed journals covering a wide range of academic disciplines. SCIRP serves the worldwide academic communities and contributes to the progress and application of science with its publication.

Other selected journals from SCIRP are listed as below. Submit your manuscript to us via either submit@scirp.org or Online Submission Portal.
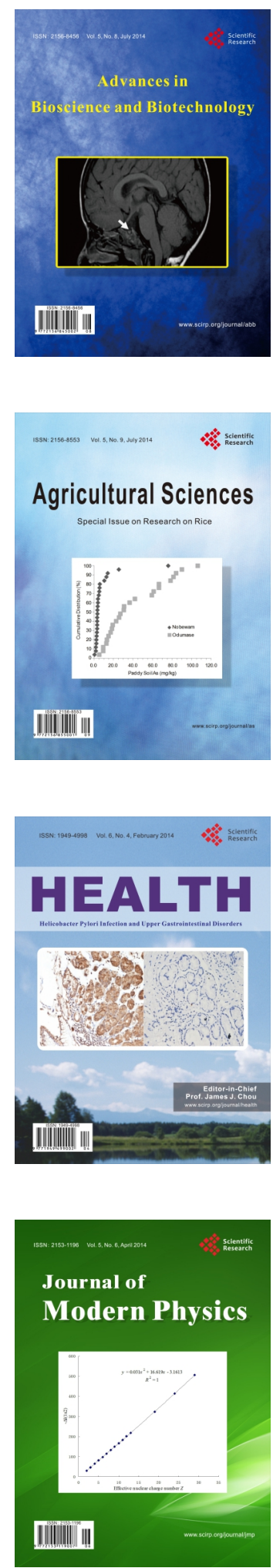
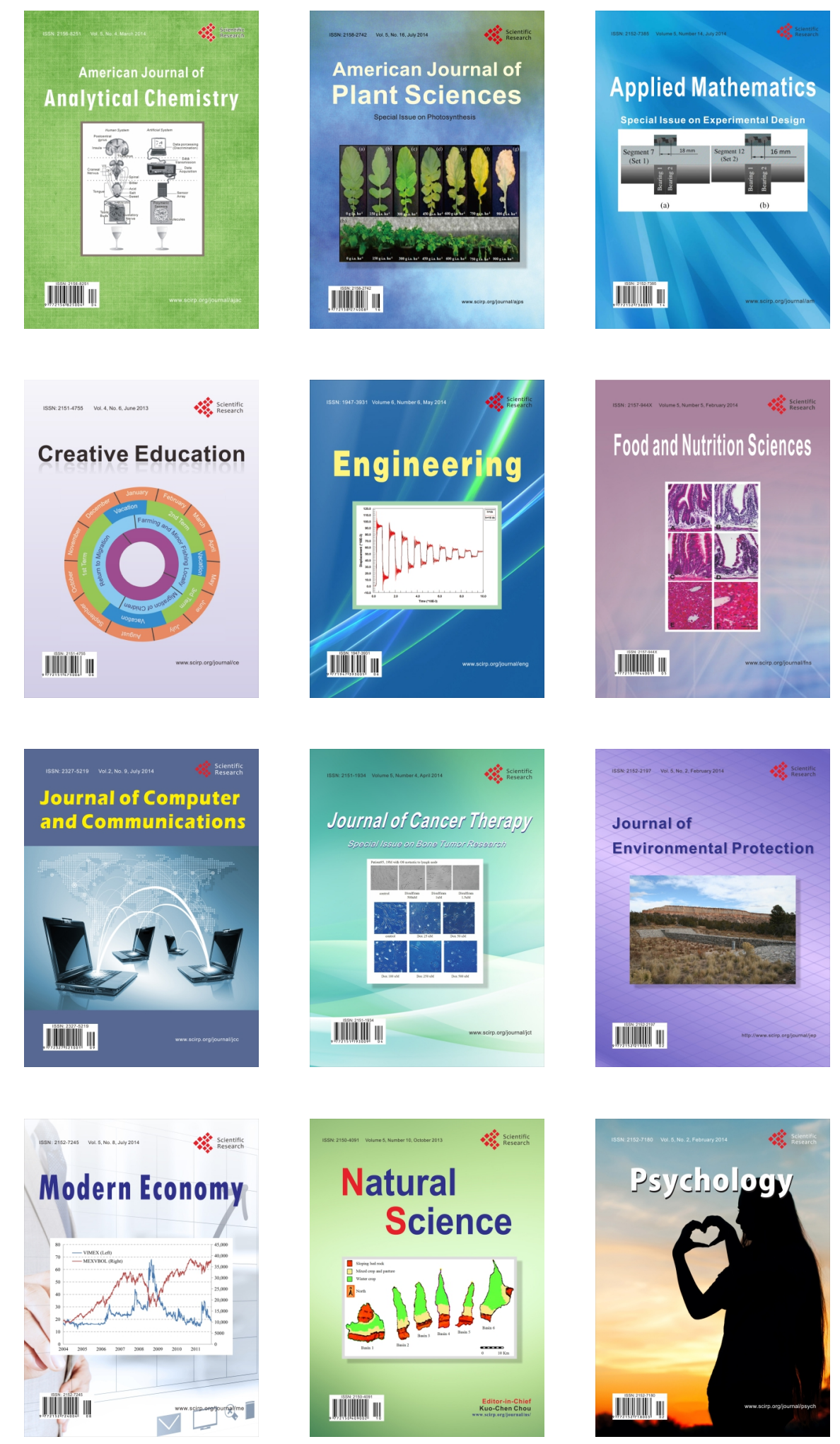